\title{
Withdrawal from Cocaine Self-Administration Normalizes Deficits in Proliferation and Enhances Maturity of Adult- Generated Hippocampal Neurons
}

\author{
Michele A. Noonan, ${ }^{1}$ Kwang H. Choi, ${ }^{2}$ David W. Self, ${ }^{1}$ and Amelia J. Eisch ${ }^{1}$ \\ ${ }^{1}$ Department of Psychiatry, University of Texas Southwestern Medical Center, Dallas, Texas 75390-9070, and ${ }^{2}$ Stanley Laboratory of Brain Research, \\ Rockville, Maryland 20850
}

\begin{abstract}
Relapse, a major problem in the treatment of cocaine addiction, is proposed to result in part from neuroadaptations in the hippocampus. We examined how a mediator of hippocampal neuroplasticity, adult neurogenesis in the subgranular zone (SGZ), was regulated by cocaine self-administration (CSA), and whether these changes were reversed by 4 weeks of withdrawal (CSA-WD) versus continued cocaine self-administration (CSA-CONT). Rats self-administered intravenous cocaine or saline for 3 weeks and were killed $2 \mathrm{~h}$ (CSA) or 4 weeks (CSA-WD, CSA-CONT) after injection with the S-phase marker bromodeoxyuridine (BrdU). Cells in several stages of adult neurogenesis were quantified: proliferating cells labeled by $\operatorname{BrdU}(2 \mathrm{~h})$ or Ki-67; immature neurons labeled by doublecortin; and adultgenerated neurons labeled with BrdU ( 4 weeks) and the mature neuronal marker NeuN. CSA decreased proliferation in both the SGZ and the subventricular zone (SVZ), a source of adult-generated olfactory neurons, changes reversed by CSA-WD. Unexpectedly, CSA-WD and CSA-CONT resulted in more immature doublecortin-immunopositive $(+)$ neurons in the posterior SGZ and a normal number of adultgenerated BrdU+ neurons in the SGZ, suggesting an enduring impact of CSA regardless of whether cocaine intake was stopped or continued. However, only CSA-WD rats had more adult-generated neurons with punctate BrdU staining, an indicator of enhanced maturity. These data suggest a mechanism for the cognitive and olfactory deficits seen in cocaine addicts, and further suggest that adult-generated neurons should be considered for their potential role in cocaine addiction and hippocampal-mediated relapse after cocaine withdrawal.
\end{abstract}

Key words: doublecortin; hippocampus; addiction; BrdU; subgranular zone; subventricular zone

\section{Introduction}

Cocaine addiction takes a devastating toll on society (Chychula and Okore, 1990). Cocaine-induced neuroadaptations are the focus of much research, as they may indicate novel treatment options for the persistent cognitive (Garavan and Hester, 2007) and olfactory deficits (Bauer and Mott, 1996; Podskarbi-Fayette et al., 2005) as well as the enormous incidence of relapse (Aharonovich et al., 2006) seen in addicts.

One neuroadaptation that may contribute to the constellation of deficits seen in cocaine addicts is altered adult neurogenesis. The adult subgranular (SGZ) and subventricular zones (SVZ) give rise to hippocampal granule and olfactory bulb neurons, respectively (Doetsch and Hen, 2005). As detailed previously (Powrozek et al., 2004; Eisch and Harburg, 2006), mounting ev-

\footnotetext{
Received March 15, 2007; revised Jan. 10, 2008; accepted Jan. 29, 2008.

We thank Drs. Danielle Graham and Scott Russo and members of the Eisch Laboratory, particularly Nathan DeCarolis and Dr. Diane Lagace, for critical reading of this manuscript. This work was supported by National Institute of Drug Abuse Grants R01 DA016765 and K02 DA023555 (A.J.E.), DA10460 (K.H.C., D.W.S.), DA18743 and DA08227 (D.W.S.), and T32 DA07290 (M.A.N.).

Correspondence should be addressed to Amelia J. Eisch, Department of Psychiatry, University of Texas Southwestern Medical Center, 5323 Harry Hines Boulevard, Dallas, TX 75390-9070. E-mail: amelia.eisch@utsouthwestern.edu.

DOI:10.1523/JNEUROSCI.4661-07.2008

Copyright $\odot 2008$ Society for Neuroscience $\quad 0270-6474 / 08 / 282516-11 \$ 15.00 / 0$
}

idence suggests adult neurogenesis plays a role in addiction. Briefly, experimenter-delivered intraperitoneal cocaine decreases SGZ proliferation (Yamaguchi et al., 2005; Dominguez-Escriba et al., 2006) in a dose- and time-dependent manner (Eisch, 2002). Also, the hippocampus is implicated in cocaine addiction and relapse (Canales, 2007), perhaps via drug-specific contextual memory formation. The link with addiction is not restricted to hippocampal neurogenesis. Modulation of SGZ and SVZ neurogenesis impacts hippocampal-based cognitive function (Kitabatake et al., 2007) and olfaction (Lledo and Saghatelyan, 2005), respectively, similar to the deficits seen after cocaine.

Although the relationship between cocaine addiction and neurogenesis is intriguing, evaluation of its verity is hampered by major gaps in our knowledge. Experimenter-delivered cocaine decreases SGZ proliferation, but it is not known whether the more clinically relevant paradigm of cocaine self-administration influences neurogenesis. Self-administration of other abused drugs alters SGZ neurogenesis (Eisch et al., 2000; Abrous et al., 2002; Crews et al., 2004), but cocaine deserves specific attention given its unique blockade of monoamine and indolamine transporters (Hummel and Unterwald, 2002). It is also not known whether cocaine-induced olfactory deficits, seen regardless of route of administration (Podskarbi-Fayette et al., 2005), are linked to cocaine-induced inhibition of SVZ neurogenesis. Neu- 
rogenesis is a process, not a time point (Abrous et al., 2005), but no study has quantified cocaine's impact on several stages of neurogenesis (Kempermann et al., 2004). Finally, it is not known how cocaine withdrawal influences SGZ and SVZ neurogenesis; this is vital to identifying if and how cocaine-induced alterations in neurogenesis contribute to relapse. As new neurons in the SGZ and olfactory bulb are well positioned to influence the reward pathway (Canales, 2007; Ubeda-Banon et al., 2007), answers to these questions may reveal if adult neurogenesis is a novel target for the treatment and perhaps prevention of addiction.

Here, we examine the effects of cocaine self-administration (CSA) on adult neurogenesis. We compare changes after 3 weeks of self-administration with changes that persist or arise after 4 weeks of either withdrawal (CSA-WD) or continued cocaine selfadministration (CSA-CONT). By analyzing stages of adult neurogenesis, such as proliferation and survival of adult-generated neurons, we reveal enduring effects of cocaine selfadministration that are only partially influenced by whether drug taking stops or continues. These data suggest adult-generated neurons should be considered for their potential role in cocaine addiction and hippocampal-mediated relapse after cocaine withdrawal.

\section{Materials and Methods}

Animals. Fifty-one male Sprague Dawley rats (300-325 g; Charles River Laboratories, Kingston, NY) were individually housed in a climatecontrolled environment on a $12 \mathrm{~h}$ light/dark cycle (lights on at 7:00 A.M.). Rats were acclimated to vivarium conditions for at least 1 week before experimentation. Rats were allowed ad libitum access to water and lab chow, except during initial lever-press training as described below. All experiments were performed in accordance with the National Institutes of Health Guide for the Care and Use of Laboratory Animals in an Institutional Animal Care and Use Committee and Association for Assessment and Accreditation of Laboratory Animal Care approved facility at University of Texas Southwestern Medical Center.

Surgery. Rats were implanted with a chronic indwelling intravenous catheter (Sutton et al., 2003; Edwards et al., 2007b). Briefly, rats were anesthetized with sodium pentobarbital $(50 \mathrm{mg} / \mathrm{kg}$, i.p.) and atropine sulfate $(0.10 \mathrm{mg} / \mathrm{rat}$, s.c.) before surgical implantation of the catheter in the jugular vein. After surgery, rats received a prophylactic injection of penicillin (60,000 IU/0.2 ml, intramuscular), and antibiotic ointment was applied daily to the surgical area. Catheters were flushed daily with $0.2 \mathrm{ml}$ of heparinized $(20 \mathrm{IU} / \mathrm{ml})$ bacteriostatic saline containing gentamycin sulfate $(0.33 \mathrm{mg} / \mathrm{ml})$ to curb infection and preserve catheter patency.

Self-administration apparatus. Each operant test chamber used for selfadministration (Med Associates, Georgia, VT) was enclosed in a ventilated, sound-attenuating box. Boxes were equipped with a Razel (Stamford, CT) model A injection pump and a $10 \mathrm{ml}$ glass syringe connected to a fluid swivel (Instech, Plymouth, PA) with Teflon tubing. Tygon tubing connected the swivel to the rat's catheter exit port and was enclosed by a metal spring secured to Teflon threads on the catheter assembly. Each operant chamber contained two response levers located $2 \mathrm{~cm}$ off the floor. During self-administration, a response at the active lever delivered an intravenous cocaine infusion (or for control rats, a saline infusion), whereas a response at the inactive lever had no programmed consequence. Each cocaine or saline infusion was delivered over $5 \mathrm{~s}$ in a $0.1 \mathrm{ml}$ volume. During the $5 \mathrm{~s}$ infusion, a cue light above the lever was illuminated and the house light was extinguished. This cue period was followed by an additional $10 \mathrm{~s} \mathrm{time-out} \mathrm{interval} \mathrm{when} \mathrm{the} \mathrm{house} \mathrm{light} \mathrm{remained} \mathrm{off}$ and responding at the active lever had no programmed consequences. The illumination of the house light signaled the end of the $15 \mathrm{~s}$ infusion time-out interval.

Cocaine self-administration. To facilitate acquisition of cocaine selfadministration, rats were initially maintained on a restricted diet $(\sim 15 \mathrm{~g}$ of chow per day) for 3 successive days and trained to press the active lever for $45 \mathrm{mg}$ sucrose pellets until they reached acquisition criterion (100 pellets for 3 consecutive days). After food training, rats were fed ad libitum at least $1 \mathrm{~d}$ before surgical catheterization and allowed to recover for 1 week before the onset of testing.

Cocaine hydrochloride was generously provided by the National Institute on Drug Abuse (Baltimore, MD). Rats were allowed to acquire cocaine self-administration $(0.5 \mathrm{mg} / \mathrm{kg}$ infusion, i.v. $)$ on a fixed-ratio reinforcement schedule (e.g., one active lever press led to a single infusion followed by a $10 \mathrm{~s}$ time out) in $4 \mathrm{~h}$ daily sessions for 3 weeks ( 5 $\mathrm{d} /$ week). Reinforcements (delivery of drug or saline after active lever press) were capped at a maximum of 95 per $4 \mathrm{~h}$ session.

Fifty-one rats were run for self-administration (saline, $n=24$; cocaine, $n=27$ ). The data presented here are replicates of two experiments. In the first experiment, rats were randomly assigned to either CSA (3 weeks cocaine self-administration) (see Fig. $1 A$ ) or CSA-WD ( 3 weeks cocaine self-administration plus 4 weeks of withdrawal) (see Fig. $1 B$ ). The breakdown by experimental group of rats run in the first experiment was as follows: CSA, saline, $n=4$; cocaine, $n=4$; and CSA-WD, saline-WD, $n=3$; CSA-WD, $n=7$. In the second experiment, rats were run in parallel and split into three complementary groups to ensure a similar average cocaine intake the last $5 \mathrm{~d}$ before bromodeoxyuridine (BrdU) injection: CSA, CSA-WD and CSA-CONT (continuous cocaine selfadministration for 7 weeks) (see Fig. 1C). This allowed the CSA rats to serve as control for the initial BrdU labeling for the CSA-WD and CSACONT groups. The breakdown by experimental group of rats run in the second experiment was as follows: CSA, saline, $n=4$; cocaine, $n=3$; CSA-WD, saline-WD, $n=9$; CSA-WD, $n=9$; and CSA-CONT, salineCONT, $n=4$; CSA-CONT, $n=4$. Data from the two experiments were added together after statistical verification that there was no difference between the results. For example, ANOVAs for experiment and drug found no effect of experiment for CSA BrdU SGZ cell number $\left(F_{(1,11)}=\right.$ $2.01 ; p>0.05)$, CSA doublecortin $(\mathrm{DCX})+$ posterior SGZ cell number $\left.F_{(1,11)}=0.62 ; p>0.05\right)$, CSA-WD BrdU SGZ cell number $\left(F_{(1,24)}=\right.$ $0.02 ; p>0.05)$, and CSA-WD DCX + posterior SGZ cell number $\left(F_{(1,24)}\right.$ $=0.37 ; p>0.05)$. After combining the number of rats from the first and second experiment, the final number of rats in each group assessed for this study was as follows: CSA, saline, $n=8$; cocaine, $n=7$; CSA-WD, saline-WD, $n=12$; CSA-WD, $n=16$; and CSA-CONT, saline-CONT, $n=4$; CSA-CONT, $n=4$. Note that data from the control groups could not be combined because each had a discrete experience, which may result in differences in neurogenesis (Stranahan et al., 2006). For example, the saline, saline-WD, and saline-CONT groups started with 3 weeks of self-administration of saline, but then diverged with saline rats being killed $15 \mathrm{~h}$ later, and saline-WD and saline-CONT rats killed 4 weeks later. The saline-WD and saline-CONT rats, although killed at the same time, differed as saline-WD rats were left in their home cage for 4 additional weeks and saline-CONT rats allowed to self-administer saline for 4 additional weeks. Catheter patency was verified for all rats after the final self-administration session via a $0.1 \mathrm{ml}$ intravenous infusion of the shortacting barbiturate sodium methohexital $(10 \mathrm{mg} / \mathrm{ml})$, which induces a rapid loss of muscle tone.

BrdU injections and tissue preparation. As shown in Figure $1 A-C, 15 \mathrm{~h}$ after the last self-administration session, all rats in the CSA, CSA-WD, and CSA-CONT groups received one $150 \mathrm{mg} / \mathrm{kg}$ intraperitoneal injection of the S-phase marker BrdU (Boehringer Mannheim, Mannheim, Germany). The CSA group was killed $2 \mathrm{~h}$ after BrdU injection to allow quantification of proliferating cells stained via BrdU immunohistochemistry (IHC) (see Fig. 1A). In contrast, the CSA-WD and CSA-CONT groups were killed 4 weeks after BrdU injection to allow quantification and assessment of surviving neurons stained via IHC for BrdU and the neuronal marker NeuN. The only difference between the CSA-WD and CSA-CONT groups was that after the BrdU injection and before being killed 4 weeks later, the CSA-WD rats were placed in their home cages (see Fig. $1 B$ ), whereas CSA-CONT rats continued self-administration of saline or cocaine (see Fig. 1C). Rats were killed either via chloral hydrate anesthesia and intracardial perfusion with $0.1 \mathrm{M}$ PBS (5 min with 10 $\mathrm{ml} / \mathrm{min}$ flow rate) and $4 \%$ paraformaldehyde in $0.1 \mathrm{M} \mathrm{PBS}(15 \mathrm{~min}$ ) or decapitation. Brains were removed and postfixed in $4 \%$ paraformaldehyde in $0.1 \mathrm{M}$ PBS for at least $24 \mathrm{~h}$ at $4^{\circ} \mathrm{C}$. Brains were cryoprotected in $30 \%$ sucrose in $0.1 \mathrm{M} \mathrm{PBS}$ with $0.1 \% \mathrm{NaN}_{3}$ at $4^{\circ} \mathrm{C}$ until coronal sectioning 
on a freezing microtome (Leica, Wetzlar, Germany) at $30 \mu \mathrm{m}$ through the entire hippocampus ( -1.80 to $-7.64 \mathrm{~mm}$ from bregma) (Paxinos and Watson, 1997) and sections were stored in $0.1 \% \mathrm{NaN}_{3}$ in $0.1 \mathrm{M} \mathrm{PBS}$ at $4^{\circ} \mathrm{C}$ until processed for IHC.

IHC. IHC was performed as described previously (Eisch et al., 2000; Mandyam et al., 2004). Briefly, every ninth section of the hippocampus was mounted on glass slides (Superfrost/Plus; Fisher Scientific, Hampton, NH) and allowed to dry overnight. Slides were coded before IHC and code was not broken until after microscopic analysis. For BrdU IHC, three pretreatment steps were used: antigen unmasking $(0.01 \mathrm{M}$ citric acid, $\left.\mathrm{pH} 6.0,95^{\circ} \mathrm{C}, 15 \mathrm{~min}\right)$, membrane permeabilization ( $0.1 \%$ trypsin in $0.1 \mathrm{M}$ Tris and $\left.0.1 \% \mathrm{CaCl}_{2}, 10 \mathrm{~min}\right)$, and DNA denaturation $(2 \mathrm{M} \mathrm{HCl}$ in $1 \times$ PBS, $30 \mathrm{~min}$ ). For Ki-67 and DCX IHC, pretreatment was limited to antigen unmasking. After pretreatment, sections were rinsed and immediately placed into blocking ( $3 \%$ serum) and then into primary antibody incubation overnight at room temperature. The primary antibodies used were rat anti-BrdU (Accurate, Westbury, NY; 1:100), mouse antiBrdU (BD Biosciences, San Jose, CA; 1:100), rabbit anti-activated caspase 3 (AC-3; Cell Signaling Technology, Beverly, MA; 1:250), rabbit antiKi-67 (Vector Laboratories, Burlingame, CA; 1:500); mouse anti-NeuN (Millipore, Billerica, MA; 1:50); and goat anti-doublecortin (Santa Cruz Biotechnology, Santa Cruz, CA; 1:3500). These antibodies were used to assess cells in stages of neurogenesis, including proliferating cells, immature and mature neurons, and cells that had undergone cell death. For example, BrdU permanently labels cells in $\mathrm{S}$ phase at time of injection (Wojtowicz and Kee, 2006) and, thus, the BrdU antibody labels proliferating cells in the CSA group (injected $2 \mathrm{~h}$ before killing) and surviving cells in CSA-WD and CSA-CONT groups (injected 4 weeks before killing). $\mathrm{Ki}-67$ is an endogenous cell cycle protein and, thus, the Ki-67 antibody labels proliferating cells in most phases of the cell cycle (Kee et al., 2002). When BrdU IHC is used to label surviving cells (e.g., BrdU given 4 weeks before killing), $\mathrm{Ki}-67 \mathrm{IHC}$ is often used as a reliable alternative and nontoxic measure of proliferation in the same tissue (Eisch and Mandyam, 2007). DCX is an endogenous cytoskeletal protein, and therefore the DCX antibody labels immature neurons (Brown et al., 2003). Finally, the NeuN antibody labels mature neurons (Mullen et al., 1992), and the AC-3 antibody labels apoptotic cells (Olney et al., 2002). Specificity of staining for each antibody was ensured by lack of signal after omission and/or dilution of primary antibody and by observation of expected subcellular localization and cellular populations stained for each antibody (Donovan et al., 2006; Lagace et al., 2006, 2007; Harburg et al., 2007).

For BrdU or Ki-67 single labeling, primary incubation was followed by incubation in a biotinylated secondary (goat anti-mouse, Sigma, St. Louis, MO; or goat anti-rabbit, Vector Laboratories; 1:200), and visualization was accomplished with the avidin-biotin/diaminobenzidine method (Pierce, Rockford, IL), followed by counterstaining with Fast red (Vector Laboratories). For BrdU and NeuN double labeling, primary incubation was followed by incubation in fluorescent secondary antibody [cyanine 3 (Cy3) donkey anti-rat, and Cy5 donkey anti-mouse; Jackson ImmunoResearch, West Grove, PA; 1:200] and counterstaining with 4,6-diamidino-2-phenylindole (DAPI; Roche, Basel, Switzerland; 1:5000) or green Nissl (Invitrogen, Carlsbad, CA; 1:200). For DCX and AC-3 double labeling, primary incubation was followed by incubation in a biotinylated secondary for DCX (horse anti-goat; Vector Laboratories; 1:200), incubation with avidin-biotin and Cy2 or Cy3 tyramide signal amplification (PerkinElmer, Norton, $\mathrm{OH}$ ), a fluorescent secondary antibody for AC-3 (Cy3 or Cy2 donkey anti-rabbit; Vector Laboratories; 1:200), and DAPI as a counterstain. Sections underwent rapid dehydration in ethanols and defatting in Citrosolv (Fisher Scientific) before coverslipping with DPX (Sigma).

Quantification of immunopositive (+) cells. BrdU+, Ki-67+, AC-3+, and DCX + cell counts were performed at $400 \times$ magnification with an Olympus (Tokyo, Japan) BX-51 microscope while continually adjusting the focal plane through the depth of the section. An observer blind to treatment group performed all cell counts.

$\mathrm{BrdU}+, \mathrm{Ki}-67+$, and AC-3+ cell counts were collected using the optical fractionator method. Briefly, exhaustive counts were collected from every ninth hippocampal section throughout the anterior-posterior ex- tent of the hippocampus ( -1.80 to $-7.64 \mathrm{~mm}$ from bregma) (Paxinos and Watson, 1997). Resulting cell counts were multiplied by the fraction of the hippocampus examined (e.g., 9) (Eisch et al., 2000; Lagace et al., 2006) and are reported as total number of cells in the brain region examined. Four discrete regions of the dentate gyrus (DG) (see Fig. $2 A$ ) were examined as previously described (Donovan et al., 2006): the SGZ, the outer granule cell layer (oGCL), the molecular layer (Mol), and the hilus (see Fig. 2 A). Immunopositive cells were also counted in the habenula to control for bioavailability of BrdU and general levels of proliferation. $\mathrm{BrdU}+$ cell densities were obtained by dividing the number of BrdU+ SGZ and oGCL cells by the volume of the anterior GCL $(-1.80$ to -4.52 $\mathrm{mm}$ from bregma) or posterior GCL $(-4.80$ to $-7.64 \mathrm{~mm}$ from bregma), with anterior-posterior demarcation as described previously (Guzman-Marin et al., 2003).

DCX + cell density quantification was restricted to two discrete points from bregma that represented the anterior $(-2.80 \mathrm{~mm}$ from bregma) and posterior $(-6.60 \mathrm{~mm}$ from bregma) dentate gyrus, respectively. These points were chosen to address specific hypotheses that emerged from our BrdU+ cell count data, allow exhaustive counting of cells at two discrete points from bregma, and to coincide with recent publications about rat DCX immunoreactivity (Driscoll et al., 2006) and anterior-posterior differences in the number of cells in stages of neurogenesis (Banasr et al., 2006; Lagace et al., 2006).

Stereological estimate of GCL and SVZ volume. Volumes of the GCL and SVZ were calculated by analyzing $30 \mu \mathrm{m}$ sections stained with Fast red (Donovan et al., 2006). Sections were coded so the experimenter was blind to treatment of the rat until completion of the analysis. All measurements were obtained using Stereoinvestigator software (MBF Bioscience, Williston, VT) and an Olympus BX51 microscope. Volumes were analyzed for the left hemisphere structure only because of previous work from our lab showing no statistical difference between the left and right hemispheres (Harburg et al., 2007).

For the GCL, the entire longitudinal axis of the hippocampus was analyzed: -1.80 to $-7.64 \mathrm{~mm}$ from bregma (Paxinos and Watson, 1997). GCL volumes were measured according to the Cavaleri principle using a $10 \times$ objective (Gundersen and Jensen, 1987; West et al., 1991). For the anterior SVZ, analysis included four sections spanning 1.60 to $-0.26 \mathrm{~mm}$ from bregma (Paxinos and Watson, 1997) (see Fig. 5A). Volumes were measured according to the Cavaleri principle using a $40 \times$ objective. The boundaries of the SVZ were based on definitions previously published (Gotts and Chesselet, 2005). Briefly, the SVZ contour included the lateral portion under the corpus callosum through the intersection of the lateral ventricle, as well as the SVZ $200 \mu \mathrm{m}$ ventral and $200 \mu \mathrm{m}$ medial to this intersection (see Fig. 5B).

Stereological estimate of SVZ Ki-67+ cell number. The optical fractionator method was used to obtain the absolute number of Ki-67+ cells in unilateral anterior SVZ (West et al., 1991; Gotts and Chesselet, 2005). A grid size of $50 \times 50 \mu \mathrm{m}^{2}$ was superimposed over each section, and $\mathrm{Ki}-67+$ cells within the SVZ were counted at $1000 \times$ in $15 \times 15 \times 6 \mu \mathrm{m}^{3}$ sample volumes, with upper and lower guard volumes of $2 \mu \mathrm{m}$, resulting in an average of 140 sampling sites per rat. Gunderson coefficients were always $<0.1$. The number of proliferating cells as measured by Ki-67 were similar to the number of proliferating cells as measured by multiple BrdU labelings in the adult rat (Gotts and Chesselet, 2005).

Phenotypic analysis. To determine the differentiation of newborn cells into neurons, CSA-WD and CSA-CONT sections were examined for the colocalization of BrdU with NeuN using confocal microscopy at $630 \times$. On average $>20 \mathrm{BrdU}+$ cells were analyzed in each rat (mean \pm SEM: saline-WD, $28.17 \pm 3.87$; CSA-WD, $26.63 \pm 2.90$; saline-CONT, $23.00 \pm$ 4.92; CSA-CONT, $41.50 \pm 6.81)$. BrdU+ nuclei were also analyzed for morphological characteristics such as nuclear pattern of BrdU staining (solid vs punctate), shape (round vs irregular), and orientation to the GCL (parallel vs perpendicular) as previous publications have linked these characteristics with maturation of the neuron (Cameron and McKay, 2001; Donovan et al., 2006).

The dendritic morphology of DCX + cells after CSA, CSA-WD, and CSA-CONT was analyzed in sections $-6.60 \mathrm{~mm}$ from bregma for characteristics previously linked to the maturity of DCX + cells (Rao et al., 2005). Specifically, every DCX + cell in the dorsal blade of the GCL 

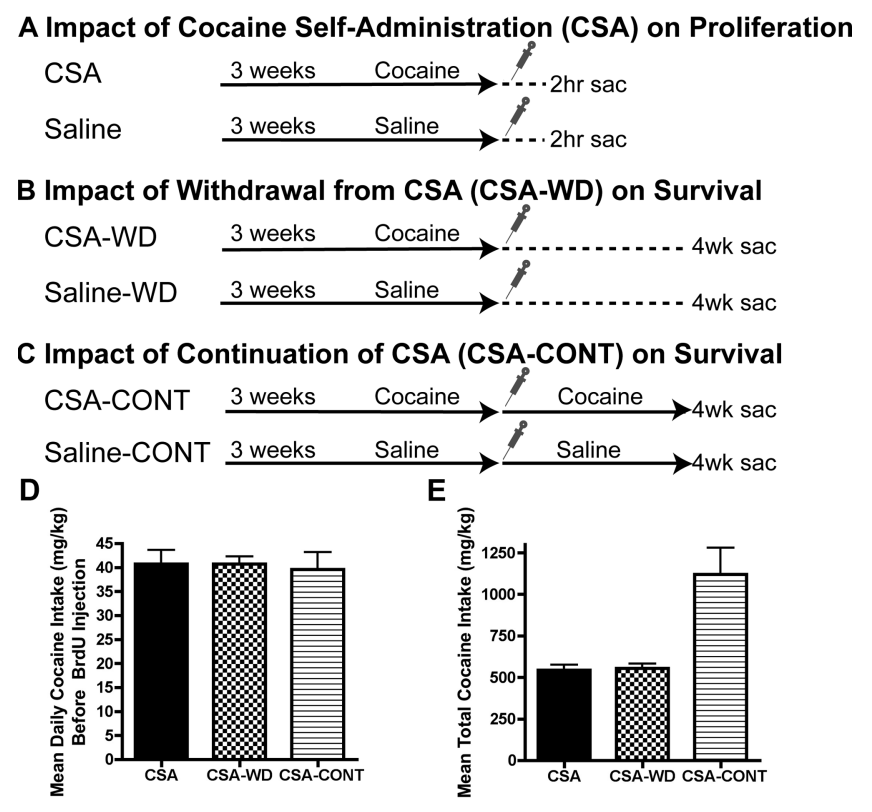

Figure 1. Experimental design. Animals were trained to lever press for intravenous saline or cocaine and then self-administered their respective solutions for 3 weeks. One BrdU injection (150 mg/kg, i.p., indicated by syringe) was administered $15 \mathrm{~h}$ after the last self-administration session. $A$, CSA and saline rats were killed $2 \mathrm{~h}$ later to assess proliferation via BrdU + cell counts. $B, C S A-W D$ and saline-WD rats were returned to their home cage and then killed 4 weeks later to assess the impact of withdrawal on survival or retention of BrdU + cells labeled 4 weeks earlier. C, CSA-CONT and saline-CONT rats continued self-administration for 4 additional weeks before rats were killed to assess the influence of cocaine on survival or retention of $\mathrm{BrdU}+$ cells labeled 4 weeks earlier. $\boldsymbol{D}$, CSA, CSA-WD, and CSA-CONT rats all self-administered the same average amount of cocaine during the last five sessions before BrdU injection. $\boldsymbol{E}$, CSA and CSA-WD rats self-administered the same total amount of cocaine, but CSA-CONT rats selfadministered more than twice as much total cocaine because of four additional weeks of sessions. Data for $\boldsymbol{D}$ and $\boldsymbol{E}$ are presented as mean \pm SEM. Sac, Sacrifice.

(mean \pm SEM: saline $82.75 \pm 8.61$, CSA $143.25 \pm 27.33$; saline-WD $39.66 \pm 9.66$, CSA-WD $72.66 \pm 22.56$; saline-CONT $81.50 \pm 19.00$, CSA-CONT 108.75 \pm 5.65 ) was examined for the presence or absence of dendrites, vertical or horizontal orientation of dendrites, and whether or not the dendrites were branched (Rao et al., 2005).

Statistical analyses and presentation. Data are represented as mean \pm SEM. Statistical analyses used GraphPad (San Diego, CA) Prism version 4.00 for Mac. A one-way ANOVA ( $t$ test) was used for analyses with one variable, such as cocaine intake, effect of drug on the density of BrdU+ or $\mathrm{DCX}+$ cells the posterior hippocampus, and effect of drug on the density of Ki-67+ cells in the SVZ. For analyses that had more than one variable (drug by dentate gyrus regions, drug by dendrite morphology), a twoway ANOVA was performed. If a main effect or interaction was found, a Bonferonni post hoc test was performed to adjust the threshold of significance to guard against the type I error, which may occur with multiple comparisons (Donovan et al., 2006). Statistical significance for main effects, interactions, and $t$ tests was defined as $p \leq 0.05$. Images were imported into Photoshop version 9.0.2 (Adobe Systems, San Jose, CA) and the only adjustments made were via gamma in the Levels function.

\section{Results}

\section{Cocaine self-administration}

Three groups of rats self-administered cocaine (CSA, CSA-WD, and CSA-CONT) with their respective control groups (saline, saline-WD, saline-CONT) self-administering saline (Fig. $1 A-C$ ). CSA, CSA-WD, and CSA-CONT rats took an average daily amount of $40 \mathrm{mg} / \mathrm{kg}$ cocaine over the last $5 \mathrm{~d}$ before injection with the S-phase marker $\operatorname{BrdU}\left(F_{(2,24)}=0.05 ; p>0.05\right)$ (Fig. $\left.1 D\right)$, indicating that cells labeled with BrdU were initially exposed to the same amount of cocaine in each group. CSA and CSA-WD rats took the same total amount of cocaine, whereas CSA-CONT rats took more than twice that amount $\left(F_{(2,24)}=25.10 ; p<\right.$ 0.001 ) (Fig. $1 E$ ); this difference was expected because the CSACONT rats self-administered for four additional weeks after the BrdU injection for a total of 7 weeks of cocaine selfadministration. Saline reinforcements for the last $5 \mathrm{~d}$ before BrdU injection were similar in controls across saline, saline-WD, and saline-CONT groups (data not shown), and were minimal because of the lack of drug reinforcement. However, the fact that saline reinforcements in this study were still measurable is likely because of the stimulation provided by the cue light that was illuminated when the active lever was pressed. In support of this, responses on the inactive lever for saline and cocaine groups, which were not reinforced with drug or cue light, were virtually zero during the last $5 \mathrm{~d}$ before BrdU injection.

\section{CSA decreases proliferation in the adult subgranular zone}

To determine the effect of drug taking on SGZ proliferation, CSA rats were injected with BrdU $15 \mathrm{~h}$ after the end of the last selfadministration session and killed $2 \mathrm{~h}$ later (Fig. $1 A$ ). BrdU IHC revealed a normal pattern of S-phase cells in the dentate gyrus, with BrdU+ cells most numerous in the SGZ, but also found in the outer granule cell layer, hilus, and molecular layer (Fig. $2 A$ ) as reported previously (Donovan et al., 2006; Lagace et al., 2006, 2007; Harburg et al., 2007). BrdU + cells at this proliferation time point appeared small, irregular, and in clusters for both saline and CSA groups (Fig. 2 B). However, rats that self-administered cocaine for 3 weeks had fewer BrdU + cells relative to control rats $\left(F_{(1,65)}=9.39 ; p<0.01\right)$ (Fig. $\left.2 C\right)$, with post hoc analysis revealing a significant $47 \%$ decrease specifically in the SGZ $(p<0.001)$ (Fig. 2C). BrdU + cell density significantly decreased in the posterior SGZ $(p<0.05)$ (data not shown), but not in the anterior SGZ $(p>0.05)$ (data not shown), in keeping with previous reports on anterior-posterior differences in the number of cells in stages of neurogenesis (Banasr et al., 2006; Lagace et al., 2006). Although cocaine has potent vasoconstrictive effects (Kaufman et al., 1998; Herning et al., 1999), there was no significant effect of CSA on the number of BrdU+ cells in several control regions, including those within the dentate gyrus ( $p$ values $>0.05$ for the molecular layer, outer granule cell layer, and hilus) (Fig. 2C) and the habenula $(p>0.05)$ (Fig. $2 C$ ). Therefore, the CSA-induced decrease in SGZ proliferation was not caused by decreased BrdU passage across the blood-brain barrier.

Quantification of AC-3+ cells showed no significant difference between CSA and saline rats in the SGZ, indicating cell death was not changed after CSA (saline, $16.88 \pm 7.30$; CSA, $25.71 \pm$ $13.81 ; p>0.05)$. To address whether the CSA-induced decreased in proliferation (Fig. 2 C) led to a decrease in GCL volume, stereological estimates of the volume of the GCL were examined. GCL volumes were consistent with previous studies with adult rats (Isgor and Sengelaub, 1998). However, analysis revealed no significant change in volume of the GCL after CSA (saline, $2.12 \pm$ 0.21 ; CSA, $\left.2.16 \pm 0.17 \mathrm{~mm}^{3} ; p>0.05\right)$. Therefore, 3 weeks of CSA decreased SGZ proliferation in a region-specific manner without influencing cell death or GCL volume.

\section{CSA does not alter the number or dendritic morphology of} immature neurons in the adult subgranular zone

As CSA decreased the number of proliferating SGZ cells, we next investigated if immature SGZ neurons, as labeled by DCX (Brown et al., 2003), were altered by CSA. DCX + staining was present in both cell bodies and processes in both saline and CSA rats (Fig. $2 D$ ). We then quantified the density of DCX + cells in 
the anterior SGZ (-2.80 $\mathrm{mm}$ from bregma), where proliferation as measured by $\mathrm{BrdU}+$ cells was not significantly changed, and in the posterior SGZ $(-6.60 \mathrm{~mm}$ from bregma) where proliferation was significantly decreased (data not shown). After CSA, the density of DCX + cells in the SGZ showed a trend for an increase in the anterior hippocampal section, with no change in the posterior section (anterior, 38\% increase, $p=0.06$; posterior, $p>0.05$ ) (Fig. $2 E)$.

We examined the dendritic morphology of DCX + cells in a posterior hippocampal section $-6.60 \mathrm{~mm}$ from bregma. Previous work has shown that a $\mathrm{DCX}+$ cell with a vertical, branched dendrite is more mature than a DCX + cell that lacks a dendrite or whose dendrites are horizontal or unbranched (Rao and Shetty, 2004). Saline rats exhibited percentages of DCX + cells with vertically oriented dendrites that were consistent with the literature (Rao et al., 2005). Analyses of saline and CSA rats revealed a main effect of drug $\left(F_{(1,39)}=6.86 ; p<0.05\right)$ (Fig. $\left.2 F\right)$, but no post hoc analyses were significant. Therefore, 3 weeks of CSA did not significantly influence the dendritic morphology of $\mathrm{DCX}+$ neurons in the posterior hippocampus.

CSA-WD normalizes proliferation and survival of adult-generated neurons in the subgranular zone, but enhances maturity of adult-generated neurons Because CSA decreased SGZ proliferation (Fig. 2C), we then examined the CSA-WD group to see whether cessation of cocaine self-administration for 4 weeks normalized SGZ proliferation. BrdU was given to the CSA-WD group at the same time as the CSA group, but whereas CSA rats were killed $2 \mathrm{~h}$ later, CSA-WD rats were killed 4 weeks later (Fig. $1 B$ ). Thus, BrdU+ cells in the CSA-WD group represented surviving, not proliferating, cells. Proliferating SGZ cells in the CSA-WD group were detected with an antibody against Ki-67, an endogenous marker of proliferation that has been used interchangeably with BrdU antibodies to detect cells labeled with BrdU $2 \mathrm{~h}$ before rats were killed (Kee et al., 2002). $\mathrm{Ki}-67+$ cells were small and often clustered (Fig. 3A) and were qualitatively similar in the SGZ of CSA-WD rats and controls. There was no significant change in Ki-67+ cell number after CSA-WD, although there was a trend for an effect of drug $\left(\mathrm{F}_{(1,130)}\right.$ $=3.46 ; p=0.06$ ) (Fig. $3 B$ ). As proliferation was decreased by $47 \%$ in CSA rats relative to controls (Fig. 2 C), the normal level of SGZ proliferation after CSA-WD suggested that proliferation rebounded at some point between the initial cessation of CSA and the 4 week withdrawal time point. Cell death was not changed after CSA-WD, as assessed via cell counts for AC-3+ cells (salineWD, $13.15 \pm 8.26$; CSA-WD, $21.71 \pm 7.60 ; p>0.05)$. This suggests that the normalization of proliferation in the SGZ is not
B

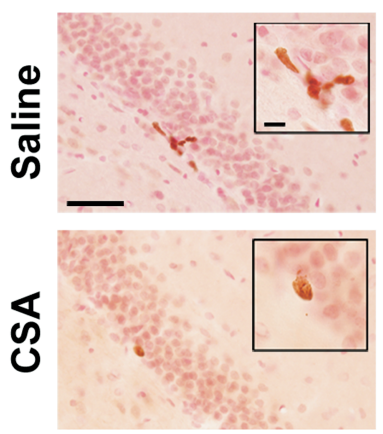

D

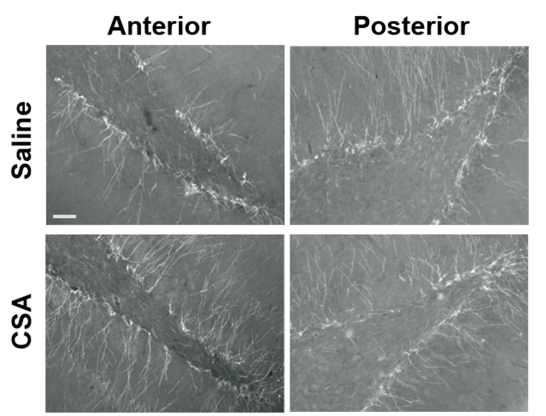

$\mathbf{F}$

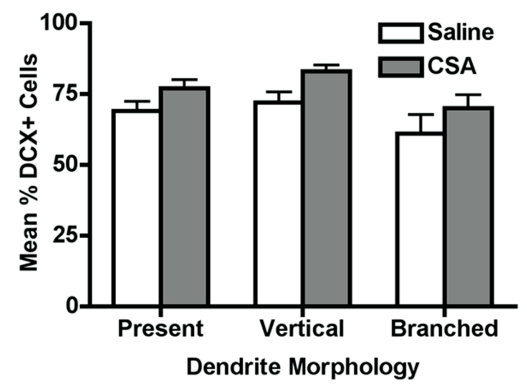

Figure 2. CSA decreases proliferation in the $S G Z$, but does not alter $D C X+$ neuron number or dendritic morphology. $\boldsymbol{A}$, Schematic of the four regions of the dentate gyrus and medial habenula in which cell counts were collected for this study. $\boldsymbol{B}$, Representative images at a proliferation time point ( $2 \mathrm{~h}$ post BrdU) injection show the decreased number of BrdU + cells in the ( Quantitative analysis of BrdU + cells in the dentate gyrus after CSA found a decrease in proliferation specific to the SGZ. D, Representative images of $D C X+$ cells in the $S G Z$ at an anterior section $(-2.80 \mathrm{~mm}$ from bregma) and posterior section $(-6.60$ $\mathrm{mm}$ from bregma) show staining of both the cell bodies and processes in both saline and CSA rats. Scale bar, $50 \mu \mathrm{m}$. $\boldsymbol{E}$, morphology of DCX + cells in the posterior SGZ. Data for $C, E$, and $\boldsymbol{F}$ are presented as mean \pm SEM. Data in C multiplied by fraction of sections examined to result in BrdU+ cell number. ${ }^{* * *} p<0.001$.

caused by a compensatory decrease in cell death after 4 weeks of withdrawal, although compensation may have occurred at other time points not assessed.

Although the number of proliferating SGZ cells was relatively normal after CSA-WD, we investigated whether cells generated during CSA (e.g., labeled with BrdU 4 weeks earlier) were influenced by the 4 -week withdrawal period after self-administration (Fig. $1 B$ ). The CSA and CSA-WD groups both received BrdU injections $15 \mathrm{~h}$ after 3 weeks of self-administration. Therefore we predicted CSA-induced decrease in the number of proliferating BrdU + cells (Fig. 2C) would equate with fewer surviving BrdU+ cells in the CSA-WD group 4 weeks later. BrdU IHC revealed cells in both saline-WD and CSA-WD rats that were round and less clustered, and presented more punctate BrdU staining, typical of SGZ cells at 4 weeks after BrdU injection (Fig. 3A) (Cameron and McKay, 2001; Donovan et al., 2006)). Interestingly, after 
A

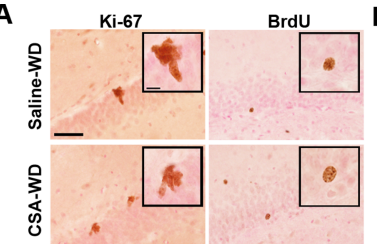

D

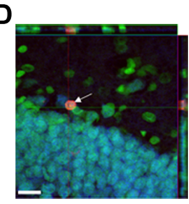

$\mathbf{F}$
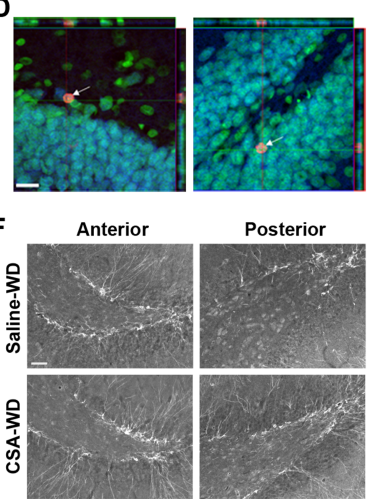

Posterior

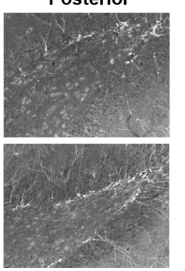

B

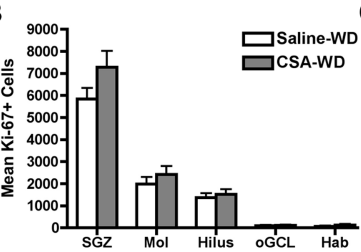

E

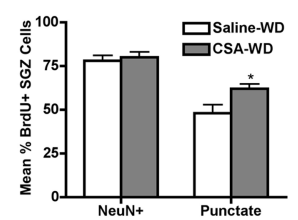

G

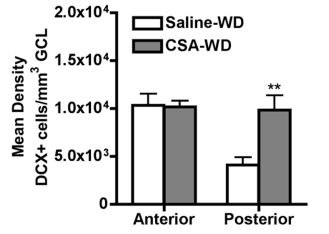

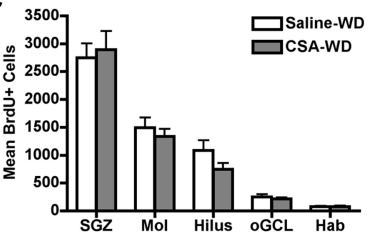

H

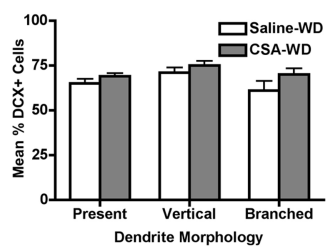

Figure 3. CSA-WD normalizes the number of proliferating cells and BrdU + adult-generated neurons in the SGZ, but increases posterior DCX + cells. $\boldsymbol{A}$, Representative images of cells immunopositive for Ki-67 (a marker of proliferation; left column) and BrdU (a marker of survival at this survival time point; right column) 4 weeks after CSA cessation. Note that many BrdU + cells at this 4 week survival time point present punctuate nuclear staining. Insets are magnification of immunopositive clusters. Scale bar, $50 \mu \mathrm{m}$; inset, $10 \mu \mathrm{m}$. B, Quantitative analysis of Ki-67+ cells revealed no significant change in any region analyzed in the number of proliferating cells after CSA-WD. C, Quantitative analysis of BrdU + cells revealed no change in the number of surviving cells in any region analyzed. $\boldsymbol{D}$, White arrows indicate BrdU+ (red) cells in representative images of the SGZ. The left and right panels depict orthogonal confocal images with $x-y, x-y$, and $y-z$ planes shown. Note that BrdU + cells are also NeuN + (neuronal marker; blue) as well as NissI + (cell body counterstain; green), indicating the majority of surviving cells had a neuronal phenotype. Scale bar, $10 \mu \mathrm{m}$. E, CSA-WD did not alter the percentage of BrdU + SGZ cells colocalizing with the neuronal marker NeuN, but the percentage of BrdU + SGZ cells that had a punctuate nuclear staining pattern significantly increased after CSA-WD. $\boldsymbol{F}$, Representative images of $D C X+$ cells in the anterior ( $-2.80 \mathrm{~mm}$ from bregma) and posterior hippocampus ( $-6.60 \mathrm{~mm}$ from bregma) after 4 weeks of CSA-WD. Scale bar, $50 \mu \mathrm{m}$. G, Quantitative analysis of density of DCX + cells after CSA-WD revealed a significant increase in the number of DCX+ cells in the posterior SGZ after CSA-WD. $\boldsymbol{H}$, CSA-WD did not change the dendritic morphology of DCX + cells in the posterior SGZ. Data for $\boldsymbol{B}, \boldsymbol{C}, \boldsymbol{E}, \mathbf{G}, \boldsymbol{H}$ are presented as the mean \pm SEM. ${ }^{*} p<0.05 ;{ }^{* *} p<0.01$. Hab, Habenula.

CSA-WD there was no effect of drug on the total number of $\operatorname{BrdU}+$ cells $\left(\mathrm{F}_{(1,130)}=0.51 ; p>0.05\right)($ Fig. $3 C)$ or on the density of BrdU + cells in the anterior or posterior SGZ ( $p$ values $>0.05$ ) (data not shown). Thus, despite the initial decrease in proliferating BrdU + SGZ cells after CSA (Fig. 2C), CSA-WD resulted in a surprising normalization of the number of surviving BrdU + SGZ cells.

The vast majority of BrdU+ cells became neurons in both control and CSA-WD rats, as indicated by double labeling with BrdU and the neuronal marker NeuN (Fig. 3D) and confocal analysis $(p>0.05)$ (Fig. 3E). Therefore, CSA-WD did not grossly influence neuronal fate of cells labeled with BrdU 4 weeks earlier. The BrdU staining pattern of the surviving BrdU + cells was also analyzed, as previous publications have linked this to maturity of the adult-generated neurons (Rietze et al., 2000; Cameron and McKay, 2001; Donovan et al., 2006). CSA-WD rats had a significantly greater percentage of cells with punctate BrdU staining (saline-WD, $48 \pm 4.85 \%$; CSA-WD, $62 \pm 2.79 \%$; $p<0.05$ ) (Fig. $3 E)$ as opposed to solid BrdU staining. Although other characteristics of cells such as shape and orientation did not differ after CSA-WD ( $p$ values $>0.05$ ), the significant increase in the proportion of BrdU + cells displaying punctate BrdU staining pattern after CSA-WD is consistent with accelerated maturation of adult-generated hippocampal granule cell neurons (Rietze et al., 2000; Cameron and McKay, 2001; Donovan et al., 2006). Thus, although CSA-WD normalized neurogenesis, as measured by the neurogenesis in the adult rat SGZ.

\section{CSA-CONT normalizes progenitor proliferation as well as} survival of adult-generated neurons in the subgranular zone without altering maturation

We hypothesized that the increased immature SGZ neuron number and enhanced maturity of surviving BrdU+ SGZ cells in CSA-WD rats was attributable to compensation that occurred during the 4 weeks of withdrawal after cocaine selfadministration. To test this, another group of rats was prepared similarly to the CSA-WD group (3 weeks of saline or cocaine self-administration and BrdU injection $15 \mathrm{~h}$ after last session), but instead of withdrawal in the home cage, these CSA-CONT rats continued to self-administer saline or cocaine for an additional 4 weeks (Fig. 1C). CSA decreased SGZ proliferation (Fig. 2C) whereas CSA-WD normalized it (Fig. 3B); thus, we expected 4 additional weeks of cocaine self-administration to sustain or further the decrease in proliferation seen after 3 weeks of cocaine self-administration. However, proliferation of Ki-67+ cells was unchanged $\left(F_{(1,30)}=1.43 ; p<0.05\right)$ (Fig. $4 A$ ). We also predicted the additional 4 weeks of cocaine self-administration in the CSACONT group would significantly decrease the number of surviving BrdU + cells. Contrary to our hypothesis, 4 additional weeks of cocaine self-administration had no effect on the total number of BrdU+ cells (drug effect, $F_{(1,30)}=2.47 ; p>0.05$ ) (Fig. $4 B$ ), although there was a trend for a decrease in the density of BrdU+ 
cells in the posterior SGZ ( $p=0.07)$ (data not shown). Neuronal fate, as indicated by double labeling with BrdU, was also unaffected by continuous self-administration of cocaine $(p>0.05)$ (Fig. $4 C)$. Other characteristics of cells, such as BrdU staining pattern $(p>0.05)$ (Fig. $4 C)$, shape and orientation did not differ after CSA-CONT $(p>0.05)$. Stereological methods were used to estimate the volume of the GCL after CSA-CONT. There was no significant change in GCL volume after CSA-CONT (saline-CONT, $2.34 \pm 0.12$; CSA-CONT, $\left.2.81 \pm 0.38 \mathrm{~mm}^{3} ; p>0.05\right)$.

CSA-CONT increases the number of immature neurons in the posterior subgranular zone

Having discovered some unexpected similarities between the impact of 4 weeks of withdrawal or 4 additional weeks of cocaine self-administration on the number of proliferating cells and adult-generated BrdU+ neurons, we then explored whether CSA-WD and CSA-CONT had similar effects on DCX + immature neuron number. After CSA-CONT, the density of DCX + cells was significantly greater in the posterior SGZ relative to controls $(-6.60 \mathrm{~mm}$ from bregma; $p=0.05)$ (Fig. $4 D)$, but not in the anterior SGZ $(-2.80$ mm from bregma; $p>0.05$ ) (Fig. $4 D$ ). Additionally, CSA-CONT did not change the dendritic morphology of DCX + cells in the posterior SGZ, as there was no main effect of drug $\left(F_{(1,18)}=0.60 ; p>0.05\right)$ (Fig. $4 E)$. Thus, similar to CSA-WD, CSACONT normalized the number of surviving BrdU+ cells and increased the number of immature neurons in the posterior SGZ without influencing their dendritic morphology. However, unlike CSA-WD, CSACONT had no effect on BrdU staining pattern of adult-generated neurons, an indicator of neuronal maturity.

\section{CSA decreases proliferation in the subventricular zone}

CSA produced such a striking decrease in hippocampal progenitor proliferation that an additional region of adult neurogenesis, the SVZ, was examined to see whether proliferation in this region was altered in a similar manner. Ki-67 IHC in the SVZ was used to assay proliferation (Fig. $5 A$ ), and the density of Ki-67 + cells was obtained via the optical fractionator method (Fig. $5 B$ ). CSA significantly decreased proliferation in the SVZ by $20 \%$ (saline, $9.76 \pm 0.49 \times$ $10^{5}$; CSA, $8.23 \pm 0.53 \times 10^{5} \mathrm{Ki}-67+$ cells $\left./ \mathrm{mm}^{3} ; p=0.05\right)$. Whereas SVZ volumes of control rats were similar to previous studies of adult rats (Gotts and Chesselet, 2005), SVZ volumes of CSA rats were not significantly different from control (saline-WD, $112.89 \pm 9.00 \times 10^{6}$; CSA, $108.42 \pm 3.56 \times 10^{6}$ ${ }^{*} p=0.05$. Hab, Habenula.
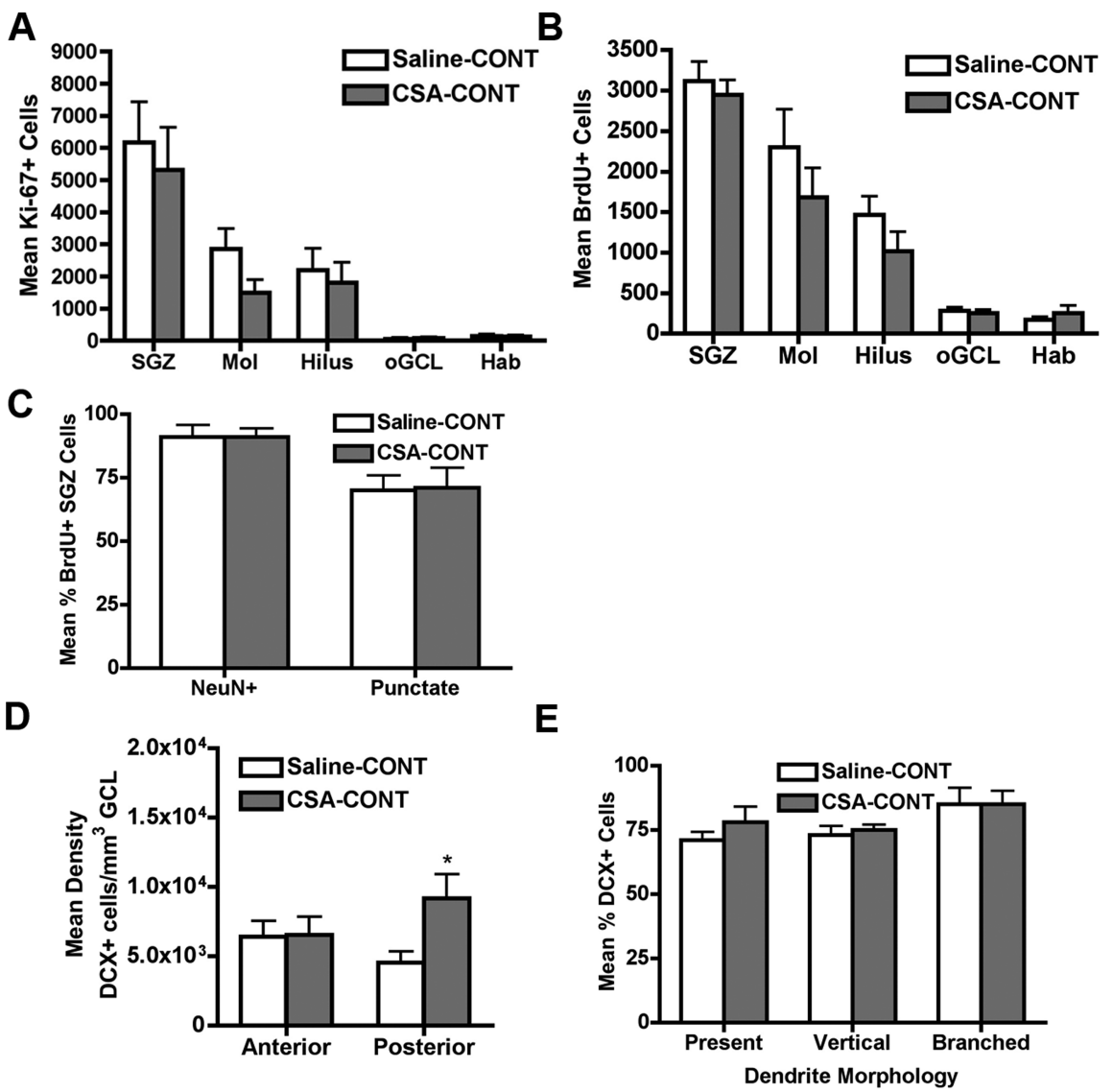

Figure 4. CSA-CONT normalizes the number of proliferating cells and BrdU + adult-generated neurons in the SGZ but increases posterior $D C X+$ cells. $A$, Quantitative analysis of Ki-67+ cells revealed no significant change in any region analyzed in the number of proliferating cells after CSA-CONT. B, Quantitative analysis of BrdU+ cells revealed no change in the number of surviving cells in the SGZ after CSA-CONT. C, CSA-CONT did not change the percentage of BrdU + SGZ cells colocalizing with the neuronal marker NeuN or displaying a punctate BrdU staining pattern. $D$, Quantitative analysis of the density of DCX + cells in the SGZ after CSA-CONT revealed a significant increase in the number of DCX + cells in the posterior SGZ after CSA-CONT. E, CSA-CONT did not change the dendritic morphology of DCX + cells in the posterior SGZ. Data for $\boldsymbol{A}-\boldsymbol{E}$ are presented as the mean \pm SEM.
A
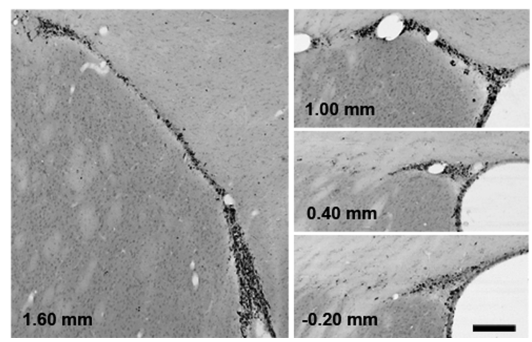

B

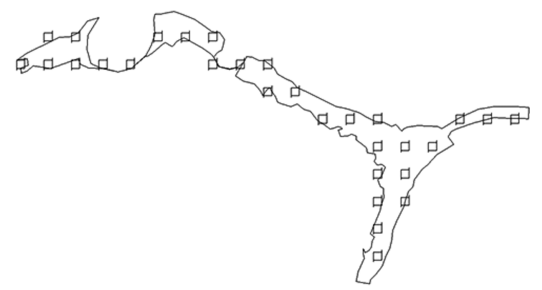

Figure 5. Stereologic quantification of Ki-67+ cells in the SVZ. $A$, Representative images of SVZ sections chosen for quantification of Ki-67+ cells with respective distances from bregma displayed in millimeters. Scale bar, $200 \mu \mathrm{m}$. $\boldsymbol{B}$, Representative outline from Stereoinvestigator of an SVZ section $1.00 \mathrm{~mm}$ from bregma shown in $\boldsymbol{A}$, depicting boundaries of SVZ as well as distribution of counting frames.

$\left.\mu \mathrm{m}^{3} ; p>0.05\right)$, suggesting that the cocaine-induced decreased in SVZ proliferation was not sufficient in magnitude or duration to impact the volume of the SVZ.

CSA-WD normalizes proliferation in the subventricular zone $\mathrm{Ki}-67+$ cells in the SVZ of the CSA-WD group were quantified to see whether cessation of drug taking reversed the CSA-induced decrease in SVZ proliferation. After CSA-WD there was no 
change in proliferation in the SVZ as measured by density of Ki-67+ cells (saline-WD, $5.92 \pm 0.81 \times 10^{5}$; CSA-WD, $5.72 \pm$ $0.72 \times 10^{5} \mathrm{Ki}-67+$ cells $\left./ \mathrm{mm}^{3} ; p>0.05\right)$. Additionally, after CSA-WD there was no change in SVZ volume as estimated by optical fractionator (saline-WD, $119.34 \pm 5.35 \times 10^{6}$, CSA-WD, $\left.121.59 \pm 6.47 \times 10^{6} \mu \mathrm{m}^{3} ; p>0.05\right)$. Therefore, 4 weeks of withdrawal is sufficient to normalize the level of SVZ proliferation.

\section{Discussion}

Our data highlight how cells in stages of adult hippocampal neurogenesis (proliferating cells, immature neurons, and surviving, adult-generated, mature neurons) are differentially influenced by intravenous cocaine self-administration and/or withdrawal. Proliferation in both the SGZ and SVZ is decreased after 3 weeks of cocaine self-administration, and 4 weeks of withdrawal reverses these changes. Neither the number or dendritic morphology of immature SGZ neurons are immediately influenced by cocaine self-administration, but surprisingly, the number of immature SGZ neurons is increased after 4 weeks of withdrawal or 4 additional weeks of cocaine self-administration. The number of surviving BrdU + cells in the SGZ is normal after either 4 weeks of withdrawal or 4 additional weeks of cocaine self-administration, but the surviving BrdU+ neurons after 4 weeks of withdrawal unexpectedly display an indicator of enhanced maturity. These data add to the growing amount of evidence that cells in discrete stages of adult neurogenesis can be independently regulated (Garcia et al., 2004; Plumpe et al., 2006; Nacher et al., 2007). Importantly, given that adult-generated granule cells are important for aspects of hippocampal function (Leuner et al., 2006; Saxe et al., 2006; Kee et al., 2007) and that the hippocampus is important in addiction and withdrawal (Goto and Grace, 2005; Rademacher et al., 2006; Rogers and See, 2007), our data urge consideration of how cocaine-induced alterations in adult neurogenesis arise, and how they may impact hippocampal function in general, and drug taking and relapse in particular.

\section{Proliferating cells}

We considerably extend previous results with noncontingent, intraperitoneal cocaine by showing that the more clinically relevant paradigm of reinforcement-related, intravenous cocaine selfadministration decreases proliferation in the adult SGZ. We further show the CSA-induced decrease in proliferation is not attributable to decreased BrdU bioavailability, an important concern given the action of cocaine on the vasculature. This decrease is likely not caused by cell death, an interpretation supported by previous cocaine work (Dominguez-Escriba et al., 2006). However, the trend in and high variability of the AC-3 data encourage future examination of additional time points after cocaine selfadministration. An additional novel neuroadaptation we identify after cocaine self-administration is decreased SVZ proliferation. Finally, both we show the decreased proliferation in the SGZ and SVZ are reversed by 3 weeks of withdrawal, indicating the homeostatic capabilities of the populations of dividing cells and/or of the neurogenic niche.

It is tempting to speculate that cocaine-induced dysregulation of adult hippocampal proliferation contributes to the cognitive deficits seen in cocaine addicts. However, this hypothesis requires in-depth clinical and translational research, and basic research to reveal the detailed time course of the impact of cocaine on proliferation and to explore how proliferating SGZ cells might influence the hippocampal neurogenic niche. The functional relevance of cocaine-induced alterations in neurogenesis may be clearer in the SVZ, as the addition of new SVZ neurons to the olfactory bulb incontrovertibly enhances aspects of olfaction (Gheusi et al., 2000; Shingo et al., 2003; Enwere et al., 2004). In humans, cocaine use impairs olfactory function, which improves with abstinence (Gordon et al., 1990; Bauer and Mott, 1996). Notably, both intravenous cocaine in humans and intraperitoneal cocaine in rats alter olfaction (Stripling and Ellinwood, 1977; Podskarbi-Fayette et al., 2005), thus addressing the apparent confound of nasal septum damage seen after intranasal cocaine use (Schwartz et al., 1989). An interesting, but as-yet untested, hypothesis is that cocaine-induced deficits in olfaction are secondary to decreased SVZ proliferation and the consequential decrease in adult-generated olfactory bulb neurons.

\section{Immature neurons}

One of our most surprising findings was that both CSA-WD and CSA-CONT result in a greater number of immature neurons specifically in the posterior SGZ. As this occurred regardless of whether drug taking continued or stopped, this may reflect a delayed response to, and long-lasting, stable neuroadaptation resulting from, cocaine self-administration. This interpretation is supported by studies with noncontingent cocaine exposure, which find a transient increase in immature neuron number (Mackowiak et al., 2005), but no effect on immature neuron dendritic morphology (Dominguez-Escriba et al., 2006). Although beyond the scope of this study, studies are required to identify whether immature neurons in particular, and neurogenesis in general, are differentially regulated during acquisition, maintenance, and long-term administration of cocaine and withdrawal, as has been shown with other neuroadaptations (Ferrario et al., 2005).

As immature neurons are important to hippocampal structure and function (Markakis and Gage, 1999; Esposito et al., 2005), it is intriguing to consider how a greater number of immature neurons in the posterior SGZ might impact hippocampal function. The posterior SGZ receives many limbic projections, and is more involved in emotion relative to the anterior SGZ, which plays a greater role in spatial processing (Sahay and Hen, 2007). Doublecortin regulates synaptic plasticity (Nacher et al., 2001; Brown et al., 2003), and adult-generated DCX + neurons possess distinct properties from granule cells generated in the early postnatal period (Wang et al., 2000; Snyder et al., 2001; Couillard-Despres et al., 2006), including lowered threshold for induction of long-term potentiation (LTP). Therefore, it is possible that having more immature neurons would lead to enhanced excitability of the hippocampus. This would fit well with the fact that chronic cocaine self-administration may increase hippocampal neurotransmitter release (Edwards et al., 2007a) and LTP (Thompson et al., 2004; del Olmo et al., 2006). Behaviorally, a greater number of immature neurons may be related to the ability of cocaine to modulate hippocampal influence over reward circuitry and goal-directed behavior (Vorel et al., 2001; Sun and Rebec, 2003; Fuchs et al., 2005; Goto and Grace, 2005) and memory (Kilts et al., 2001; Hester et al., 2006; Del Olmo et al., 2007). Additional study is needed to determine the functional role of increased DCX + cells in the posterior SGZ in the encoding of contextual associations with drug taking, as these associations are a major obstacle in addiction treatment.

\section{Surviving, adult-generated, mature neurons}

Although 3 weeks of cocaine self-administration robustly decreased SGZ proliferation, it is striking that 4 weeks later, with or without continuation of cocaine self-administration, the number 
of surviving BrdU+ neurons in the SGZ is normal relative to saline self-administering controls. When analyzed in just the posterior SGZ, there was a trend to a decrease in CSA-CONT rats, encouraging additional analyses to pinpoint differences between CSA-WD and CSA-CONT. However, given the lack of change when the SGZ was considered as a whole, clearly some level of compensation must have occurred for the decreased population of progenitors after 3 weeks of CSA to result in normal numbers of surviving BrdU+ neurons after 4 weeks of withdrawal and 4 additional weeks of cocaine. A decrease in cell death is unlikely, as we found no change in $\mathrm{AC}-3+$ cells, although it is possible that we missed the narrow window in which cell death is detectable (Harburg et al., 2007) or that the low basal rate of apoptosis in the adult SGZ results in a floor effect for detecting further decreases in cell death (Heine et al., 2004). Alternatively, the decreased pool of progenitors could have divided more frequently or symmetrically, giving rise to two daughter cells more often than one. Both scenarios would result in the normal number of surviving BrdU + neurons in the SGZ of CSA-WD and CSA-CONT rats reported here.

Aside from the many surprising similarities between the CSA-WD and CSA-CONT groups, an abstinence-specific neuroadaptation worth noting is the enhanced maturity of adultgenerated BrdU+ neurons after withdrawal. This suggests a benefit of abstinence for the dentate gyrus, but clearly encourages functional exploration of this putative enhanced maturity as well as identification of other neuroadaptations during CSA-WD or CSA-CONT that may be compensatory, encouraging a return to homeostasis.

\section{Conclusion}

The present study defines the novel impact of cocaine selfadministration and/or withdrawal on cells in various stages of adult neurogenesis. Although detailed discussion about underlying mechanisms is speculative, it is likely that cocaine selfadministration and/or withdrawal alters the microenviroment of the neurogenic niche, (Abrous et al., 2005; Ming and Song, 2005), perhaps via alterations in levels of growth factors. A potential role for brain-derived neurotrophic factor (BDNF) is particularly intriguing, because BDNF signaling regulates cocaine selfadministration (Graham et al., 2007), incubation of drug craving (Grimm et al., 2003), and specifically in the dentate gyrus, the acquisition of stimulant/context associations and conditioned locomotor sensitization (Rademacher et al., 2006; Shen et al., 2006). Although BDNF is one of many candidates, clearly understanding cocaine-induced alterations in the neurogenic microenvironment may point to a critical role for dentate gyrus neurogenesis in cocaine cravings and relapse, perhaps via facilitation of recall of contextual associations that stimulate cocaine cravings and relapse.

It will be interesting in the future to test whether manipulations of neurogenesis can alter the propensity for addictive behavior. Such studies await refinement in techniques to specifically alter adult neurogenesis with minimal side effects. It is intriguing that conditions often comorbid with substance abuse, like stress, depression, and schizophrenia (Brady and Sinha, 2005) are marked by dysregulation of adult neurogenesis (Paizanis et al., 2007). The present study establishes neurogenesis as a potential target for therapeutic approaches to drug addiction treatment which may have broad implications for psychiatric disorders.

\section{References}

Abrous DN, Adriani W, Montaron MF, Aurousseau C, Rougon G, Le Moal M, Piazza PV (2002) Nicotine self-administration impairs hippocampal plasticity. J Neurosci 22:3656-3662.

Abrous DN, Koehl M, Le Moal M (2005) Adult neurogenesis: from precursors to network and physiology. Physiol Rev 85:523-569.

Aharonovich E, Hasin DS, Brooks AC, Liu X, Bisaga A, Nunes EV (2006) Cognitive deficits predict low treatment retention in cocaine dependent patients. Drug Alcohol Depend 81:313-322.

Banasr M, Soumier A, Hery M, Mocaer E, Daszuta A (2006) Agomelatine, a new antidepressant, induces regional changes in hippocampal neurogenesis. Biol Psychiatry 59:1087-1096.

Bauer LO, Mott AE (1996) Differential effects of cocaine, alcohol, and nicotine dependence on olfactory evoked potentials. Drug Alcohol Depend 42:21-26.

Brady KT, Sinha R (2005) Co-occurring mental and substance use disorders: the neurobiological effects of chronic stress. Am J Psychiatry 162:1483-1493.

Brown JP, Couillard-Despres S, Cooper-Kuhn CM, Winkler J, Aigner L, Kuhn HG (2003) Transient expression of doublecortin during adult neurogenesis. J Comp Neurol 467:1-10.

Cameron HA, McKay RD (2001) Adult neurogenesis produces a large pool of new granule cells in the dentate gyrus. J Comp Neurol 435:406-417.

Canales JJ (2007) Adult neurogenesis and the memories of drug addiction. Eur Arch Psychiatry Clin Neurosci.

Chychula NM, Okore C (1990) The cocaine epidemic: a comprehensive review of use, abuse and dependence. Nurse Pract 15:31-39.

Couillard-Despres S, Winner B, Karl C, Lindemann G, Schmid P, Aigner R, Laemke J, Bogdahn U, Winkler J, Bischofberger J, Aigner L (2006) Targeted transgene expression in neuronal precursors: watching young neurons in the old brain. Eur J Neurosci 24:1535-1545.

Crews FT, Nixon K, Wilkie ME (2004) Exercise reverses ethanol inhibition of neural stem cell proliferation. Alcohol 33:63-71.

del Olmo N, Miguens M, Higuera-Matas A, Torres I, Garcia-Lecumberri C, Solis JM, Ambrosio E (2006) Enhancement of hippocampal long-term potentiation induced by cocaine self-administration is maintained during the extinction of this behavior. Brain Res 1116:120-126.

Del Olmo N, Higuera-Matas A, Miguens M, Garcia-Lecumberri C, Ambrosio E (2007) Cocaine self-administration improves performance in a highly demanding water maze task. Psychopharmacology (Berl) 195:19-25.

Doetsch F, Hen R (2005) Young and excitable: the function of new neurons in the adult mammalian brain. Curr Opin Neurobiol 15:121-128.

Dominguez-Escriba L, Hernandez-Rabaza V, Soriano-Navarro M, Barcia JA, Romero FJ, Garcia-Verdugo JM, Canales JJ (2006) Chronic cocaine exposure impairs progenitor proliferation but spares survival and maturation of neural precursors in adult rat dentate gyrus. Eur J Neurosci 24:586-594.

Donovan MH, Yazdani U, Norris RD, Games D, German DC, Eisch AJ (2006) Decreased adult hippocampal neurogenesis in the PDAPP mouse model of Alzheimer's disease. J Comp Neurol 495:70-83.

Driscoll I, Howard SR, Stone JC, Monfils MH, Tomanek B, Brooks WM, Sutherland RJ (2006) The aging hippocampus: a multi-level analysis in the rat. Neuroscience 139:1173-1185.

Edwards S, Graham DL, Bachtell RK, Self DW (2007a) Region-specific tolerance to cocaine-regulated CAMP-dependent protein phosphorylation following chronic self-administration. Eur J Neurosci 25:2201-2213.

Edwards S, Whisler KN, Fuller DC, Orsulak PJ, Self DW (2007b) Addictionrelated alterations in $\mathrm{d}(1)$ and $\mathrm{d}(2)$ dopamine receptor behavioral responses following chronic cocaine self-administration. Neuropsychopharmacology 32:354-366.

Eisch AJ (2002) Adult neurogenesis: implications for psychiatry. Prog Brain Res 138:315-342.

Eisch AJ, Harburg GC (2006) Opiates, psychostimulants, and adult hippocampal neurogenesis: Insights for addiction and stem cell biology. Hippocampus 16:271-286.

Eisch AJ, Mandyam CD (2007) Adult neurogenesis: can analysis of cell cycle proteins move us "Beyond BrdU”? Curr Pharm Biotechnol 8:147-165.

Eisch AJ, Barrot M, Schad CA, Self DW, Nestler EJ (2000) Opiates inhibit neurogenesis in the adult rat hippocampus. Proc Natl Acad Sci USA 97:7579-7584.

Enwere E, Shingo T, Gregg C, Fujikawa H, Ohta S, Weiss S (2004) Aging results in reduced epidermal growth factor receptor signaling, diminished 
olfactory neurogenesis, and deficits in fine olfactory discrimination. J Neurosci 24:8354-8365.

Esposito MS, Piatti VC, Laplagne DA, Morgenstern NA, Ferrari CC, Pitossi FJ, Schinder AF (2005) Neuronal differentiation in the adult hippocampus recapitulates embryonic development. J Neurosci 25:10074-10086.

Ferrario CR, Gorny G, Crombag HS, Li Y, Kolb B, Robinson TE (2005) Neural and behavioral plasticity associated with the transition from controlled to escalated cocaine use. Biol Psychiatry 58:751-759.

Fuchs RA, Evans KA, Ledford CC, Parker MP, Case JM, Mehta RH, See RE (2005) The role of the dorsomedial prefrontal cortex, basolateral amygdala, and dorsal hippocampus in contextual reinstatement of cocaine seeking in rats. Neuropsychopharmacology 30:296-309.

Garavan H, Hester R (2007) The role of cognitive control in cocaine dependence. Neuropsychol Rev 17:337-345.

Garcia A, Steiner B, Kronenberg G, Bick-Sander A, Kempermann G (2004) Age-dependent expression of glucocorticoid- and mineralocorticoid receptors on neural precursor cell populations in the adult murine hippocampus. Aging Cell 3:363-371.

Gheusi G, Cremer H, McLean H, Chazal G, Vincent JD, Lledo PM (2000) Importance of newly generated neurons in the adult olfactory bulb for odor discrimination. Proc Natl Acad Sci USA 97:1823-1828.

Gordon AS, Moran DT, Jafek BW, Eller PM, Strahan RC (1990) The effect of chronic cocaine abuse on human olfaction. Arch Otolaryngol Head Neck Surg 116:1415-1418.

Goto Y, Grace AA (2005) Dopamine-dependent interactions between limbic and prefrontal cortical plasticity in the nucleus accumbens: disruption by cocaine sensitization. Neuron 47:255-266.

Gotts JE, Chesselet MF (2005) Mechanisms of subventricular zone expansion after focal cortical ischemic injury. J Comp Neurol 488:201-214.

Graham DL, Edwards S, Bachtell RK, Dileone RJ, Rios M, Self DW (2007) Dynamic BDNF activity in nucleus accumbens with cocaine use increases self-administration and relapse. Nat Neurosci 10:1029-1037.

Grimm JW, Lu L, Hayashi T, Hope BT, Su TP, Shaham Y (2003) Timedependent increases in brain-derived neurotrophic factor protein levels within the mesolimbic dopamine system after withdrawal from cocaine: implications for incubation of cocaine craving. J Neurosci 23:742-747.

Gundersen HJ, Jensen EB (1987) The efficiency of systematic sampling in stereology and its prediction. J Microsc 147:229-263.

Guzman-Marin R, Suntsova N, Stewart DR, Gong H, Szymusiak R, McGinty D (2003) Sleep deprivation reduces proliferation of cells in the dentate gyrus of the hippocampus in rats. J Physiol (Lond) 549:563-571.

Harburg GC, Hall FS, Harrist AV, Sora I, Uhl GR, Eisch AJ (2007) Knockout of the mu opioid receptor enhances the survival of adult-generated hippocampal granule cell neurons. Neuroscience 144:77-87.

Heine VM, Maslam S, Joels M, Lucassen PJ (2004) Prominent decline of newborn cell proliferation, differentiation, and apoptosis in the aging dentate gyrus, in absence of an age-related hypothalamus-pituitaryadrenal axis activation. Neurobiol Aging 25:361-375.

Herning RI, Better W, Nelson R, Gorelick D, Cadet JL (1999) The regulation of cerebral blood flow during intravenous cocaine administration in cocaine abusers. Ann NY Acad Sci 890:489-494.

Hester R, Dixon V, Garavan H (2006) A consistent attentional bias for drugrelated material in active cocaine users across word and picture versions of the emotional Stroop task. Drug Alcohol Depend 81:251-257.

Hummel M, Unterwald EM (2002) D1 dopamine receptor: a putative neurochemical and behavioral link to cocaine action. J Cell Physiol 191:17-27.

Isgor C, Sengelaub DR (1998) Prenatal gonadal steroids affect adult spatial behavior, CA1 and CA3 pyramidal cell morphology in rats. Horm Behav 34:183-198.

Kaufman MJ, Levin JM, Ross MH, Lange N, Rose SL, Kukes TJ, Mendelson JH, Lukas SE, Cohen BM, Renshaw PF (1998) Cocaine-induced cerebral vasoconstriction detected in humans with magnetic resonance angiography. Jama 279:376-380.

Kee N, Sivalingam S, Boonstra R, Wojtowicz JM (2002) The utility of Ki-67 and BrdU as proliferative markers of adult neurogenesis. J Neurosci Methods 115:97-105.

Kee N, Teixeira CM, Wang AH, Frankland PW (2007) Preferential incorporation of adult-generated granule cells into spatial memory networks in the dentate gyrus. Nat Neurosci 10:355-362.

Kempermann G, Jessberger S, Steiner B, Kronenberg G (2004) Milestones of neuronal development in the adult hippocampus. Trends Neurosci 27:447-452.

Kilts CD, Schweitzer JB, Quinn CK, Gross RE, Faber TL, Muhammad F, Ely TD, Hoffman JM, Drexler KP (2001) Neural activity related to drug craving in cocaine addiction. Arch Gen Psychiatry 58:334-341.

Kitabatake Y, Sailor KA, Ming GL, Song H (2007) Adult neurogenesis and hippocampal memory function: new cells, more plasticity, new memories? Neurosurg Clin N Am 18:105-113, x.

Lagace DC, Yee JK, Bolanos CA, Eisch AJ (2006) Juvenile administration of methylphenidate attenuates adult hippocampal neurogenesis. Biol Psychiatry 60:1121-1130.

Lagace DC, Fischer SJ, Eisch AJ (2007) Gender and endogenous levels of estradiol do not influence adult hippocampal neurogenesis in mice. Hippocampus 17:175-180.

Leuner B, Gould E, Shors TJ (2006) Is there a link between adult neurogenesis and learning? Hippocampus 16:216-224.

Lledo PM, Saghatelyan A (2005) Integrating new neurons into the adult olfactory bulb: joining the network, life-death decisions, and the effects of sensory experience. Trends Neurosci 28:248-254.

Mackowiak M, Markowicz-Kula K, Fijal K, Wedzony K (2005) Acute and repeated administration of cocaine differentially regulates expression of PSA-NCAM-positive neurons in the rat hippocampus. Brain Res 1055:149-155.

Mandyam CD, Norris RD, Eisch AJ (2004) Chronic morphine induces premature mitosis of proliferating cells in the adult mouse subgranular zone. J Neurosci Res 76:783-794.

Markakis EA, Gage FH (1999) Adult-generated neurons in the dentate gyrus send axonal projections to field CA3 and are surrounded by synaptic vesicles. J Comp Neurol 406:449-460.

Ming GL, Song H (2005) Adult neurogenesis in the mammalian central nervous system. Annu Rev Neurosci 28:223-250.

Mullen RJ, Buck CR, Smith AM (1992) NeuN, a neuronal specific nuclear protein in vertebrates. Development 116:201-211.

Nacher J, Rosell DR, Alonso-Llosa G, McEwen BS (2001) NMDA receptor antagonist treatment induces a long-lasting increase in the number of proliferating cells, PSA-NCAM-immunoreactive granule neurons and radial glia in the adult rat dentate gyrus. Eur J Neurosci 13:512-520.

Nacher J, Varea E, Miguel Blasco-Ibanez J, Gomez-Climent MA, CastilloGomez E, Crespo C, Martinez-Guijarro FJ, McEwen BS (2007) $\mathrm{N}$-methyl-d-aspartate receptor expression during adult neurogenesis in the rat dentate gyrus. Neuroscience 144:855-864.

Olney JW, Tenkova T, Dikranian K, Muglia LJ, Jermakowicz WJ, D'Sa C, Roth KA (2002) Ethanol-induced caspase-3 activation in the in vivo developing mouse brain. Neurobiol Dis 9:205-219.

Paizanis E, Hamon M, Lanfumey L (2007) Hippocampal neurogenesis, depressive disorders, and antidepressant therapy. Neural Plast:73754.

Paxinos GT, Watson C (1997) The rat brain in stereotaxic coordinates, compact Ed 3. New York: Academic.

Plumpe T, Ehninger D, Steiner B, Klempin F, Jessberger S, Brandt M, Romer B, Rodriguez GR, Kronenberg G, Kempermann G (2006) Variability of doublecortin-associated dendrite maturation in adult hippocampal neurogenesis is independent of the regulation of precursor cell proliferation. BMC Neurosci 7:77.

Podskarbi-Fayette R, Rydzewski B, Lipinska M (2005) [Smell and taste in drug addicts]. Otolaryngol Pol 59:585-590.

Powrozek TA, Sari Y, Singh RP, Zhou FC (2004) Neurotransmitters and substances of abuse: effects on adult neurogenesis. Curr Neurovasc Res 1:251-260.

Rademacher DJ, Kovacs B, Shen F, Napier TC, Meredith GE (2006) The neural substrates of amphetamine conditioned place preference: implications for the formation of conditioned stimulus-reward associations. Eur J Neurosci 24:2089-2097.

Rao MS, Shetty AK (2004) Efficacy of doublecortin as a marker to analyse the absolute number and dendritic growth of newly generated neurons in the adult dentate gyrus. Eur J Neurosci 19:234-246.

Rao MS, Hattiangady B, Abdel-Rahman A, Stanley DP, Shetty AK (2005) Newly born cells in the ageing dentate gyrus display normal migration, survival and neuronal fate choice but endure retarded early maturation. Eur J Neurosci 21:464-476.

Rietze R, Poulin P, Weiss S (2000) Mitotically active cells that generate neurons and astrocytes are present in multiple regions of the adult mouse hippocampus. J Comp Neurol 424:397-408. 
Rogers JL, See RE (2007) Selective inactivation of the ventral hippocampus attenuates cue-induced and cocaine-primed reinstatement of drugseeking in rats. Neurobiol Learn Mem.

Sahay A, Hen R (2007) Adult hippocampal neurogenesis in depression. Nat Neurosci 10:1110-1115.

Saxe MD, Battaglia F, Wang JW, Malleret G, David DJ, Monckton JE, Garcia AD, Sofroniew MV, Kandel ER, Santarelli L, Hen R, Drew MR (2006) Ablation of hippocampal neurogenesis impairs contextual fear conditioning and synaptic plasticity in the dentate gyrus. Proc Natl Acad Sci USA 103:17501-17506.

Schwartz RH, Estroff T, Fairbanks DN, Hoffmann NG (1989) Nasal symptoms associated with cocaine abuse during adolescence. Arch Otolaryngol Head Neck Surg 115:63-64.

Shen F, Meredith GE, Napier TC (2006) Amphetamine-induced place preference and conditioned motor sensitization requires activation of tyrosine kinase receptors in the hippocampus. J Neurosci 26:11041-11051.

Shingo T, Gregg C, Enwere E, Fujikawa H, Hassam R, Geary C, Cross JC, Weiss S (2003) Pregnancy-stimulated neurogenesis in the adult female forebrain mediated by prolactin. Science 299:117-120.

Snyder JS, Kee N, Wojtowicz JM (2001) Effects of adult neurogenesis on synaptic plasticity in the rat dentate gyrus. J Neurophysiol 85:2423-2431.

Stranahan AM, Khalil D, Gould E (2006) Social isolation delays the positive effects of running on adult neurogenesis. Nat Neurosci 9:526-533.

Stripling JS, Ellinwood Jr EH (1977) Augmentation of the behavioral and electrophysiologic response to cocaine by chronic administration in the rat. Exp Neurol 54:546-564.
Sun W, Rebec GV (2003) Lidocaine inactivation of ventral subiculum attenuates cocaine-seeking behavior in rats. J Neurosci 23:10258-10264.

Sutton MA, Schmidt EF, Choi KH, Schad CA, Whisler K, Simmons D, Karanian DA, Monteggia LM, Neve RL, Self DW (2003) Extinction-induced upregulation in AMPA receptors reduces cocaine-seeking behaviour. Nature 421:70-75.

Thompson AM, Swant J, Gosnell BA, Wagner JJ (2004) Modulation oflongterm potentiation in the rat hippocampus following cocaine selfadministration. Neuroscience 127:177-185.

Ubeda-Banon I, Novejarque A, Mohedano-Moriano A, Pro-Sistiaga P, de la Rosa-Prieto C, Insausti R, Martinez-Garcia F, Lanuza E, MartinezMarcos (2007) A Projections from the posterolateral olfactory amygdala to the ventral striatum: neural basis for reinforcing properties of chemical stimuli. BMC Neurosci 8:103.

Vorel SR, Liu X, Hayes RJ, Spector JA, Gardner EL (2001) Relapse to cocaine-seeking after hippocampal theta burst stimulation. Science 292:1175-1178.

Wang S, Scott BW, Wojtowicz JM (2000) Heterogenous properties of dentate granule neurons in the adult rat. J Neurobiol 42:248-257.

West MJ, Slomianka L, Gundersen HJ (1991) Unbiased stereological estimation of the total number of neurons in the subdivisions of the rat hippocampus using the optical fractionator. Anat Rec 231:482-497.

Wojtowicz JM, Kee N (2006) BrdU assay for neurogenesis in rodents. Nat Protoc 1:1399-1405.

Yamaguchi M, Suzuki T, Seki T, Namba T, Liu J, Arai H, Hori T, Shiga T (2005) Decreased cell proliferation in the dentate gyrus of rats after repeated administration of cocaine. Synapse 58:63-71. 